\title{
Aripiprazole and Acute Extrapyramidal Symptoms in Children and Adolescents: A Meta-Analysis
}

\author{
Chiara Bernagie $^{1}$ (1) $\cdot$ Marina Danckaerts $^{1,2} \cdot$ Martien Wampers $^{3} \cdot$ Marc De Hert $^{2,3}$
}

Published online: 9 July 2016

(c) The Author(s) 2016. This article is published with open access at Springerlink.com

\begin{abstract}
Background Both the US FDA and the European Medicines Agency (EMA) have approved aripiprazole for use in adolescents for specific indications. Given the assumed favorable side-effect profile of aripiprazole, its use in children and adolescents has increased for both official and off-label indications (anxiety disorders, eating disorders, personality disorders). However, several cases of children and adolescents with new-onset extrapyramidal symptoms (EPS) after commencing treatment with aripiprazole have been reported, and a more systematic appraisal of this possible risk is lacking.

Objective We conducted a systematic review and a metaanalysis to assess the evidence for acute EPS (acute dystonia, akathisia, Parkinsonism) associated with the use of aripiprazole in children and adolescents.

Method We searched the MEDLINE and Embase databases (2003-10 April 2016) for clinical trials in pediatric patients (aged 0-18 years) using the keywords 'aripiprazole' (regardless of the formulation) and 'extrapyramidal symptoms'. We evaluated the abstracts of papers using the
\end{abstract}

Electronic supplementary material The online version of this article (doi:10.1007/s40263-016-0367-y) contains supplementary material, which is available to authorized users.

Chiara Bernagie

chiara.bernagie@uzleuven.be

1 Department of Child and Adolescent Psychiatry, UPC KU Leuven-Z.org KU Leuven, UPC KU Leuven campus Leuven, UZ Leuven campus Gasthuisberg, Herestraat 49, 3000 Leuven, Belgium

2 Department of Neurosciences, KU Leuven, Leuven, Belgium

3 Department of Psychiatry, UPC KU Leuven-Z.org KU Leuven, Leuven, Belgium following exclusion criteria: (1) study design: case report, letter to the editor, editorial, or poster presentation data; (2) unrelated PICOS (population, intervention, comparators, outcomes, study) structure. We performed a meta-analysis, in which we used effect sizes with $95 \%$ confidence intervals (CIs). To examine the homogeneity of the effect size distribution, we used a Q-statistic. When we observed heterogeneity in effect sizes, we assessed the possible influence of moderator variables (age and sex, mean dose, study duration, and method of measuring EPS incidence) and evaluated the suitability of either a fixed or a random model. Finally, we assessed the incidence of EPS in children and adolescents treated with aripiprazole compared with placebo.

Results An initial search via PubMed and Embase yielded 328 hits. A manual search of the reference lists of review papers revealed seven additional relevant articles. We included 41 studies, with 2114 pediatric patients, in the meta-analysis. For the analysis of the mean incidence of EPS, data were provided by 24 studies, with a total of 1446 pediatric patients. Meta-analysis revealed a mean EPS incidence of $17.1 \%$ (95\% CI 0.128-0.223). In terms of the incidence of various extrapyramidal side effects, overall, no significant effects of age, sex, mean dose, study duration, or measuring method could be demonstrated. The side effects 'EPS', 'parkinsonism', and 'tremor' were significantly more common in children and adolescents treated with aripiprazole than in those treated with placebo.

Conclusion Our meta-analysis provides evidence for a non-negligible incidence of acute EPS in children and adolescents treated with aripiprazole. Although the study has several limitations and further investigation is needed, these findings may help clinicians make more balanced treatment choices and more closely monitor the use of this drug in youth. 


\section{Key Points}

In light of recent concerns about extrapyramidal symptoms (EPS) as a potential side effect of aripiprazole, we conducted a meta-analysis to assess the incidence of EPS in children and adolescents.

We found a mean incidence of $17.1 \%$ (95\% confidence interval $0.128-0.223$ ).

This finding highlights the importance of considerate prescription of aripiprazole in youth.

\section{Introduction}

The US FDA has approved the use of aripiprazole in adolescents (aged 13-17 years) with schizophrenia, in pediatric patients (aged 10-17 years) with manic or mixed episodes associated with a bipolar I disorder (both as monotherapy and as an adjunct to lithium or valproate $[2,3])$, and for the treatment of irritability associated with autistic disorder in pediatric patients (aged 6-17 years) [4]. In Europe, the use of aripiprazole is approved by the European Medicines Agency (EMA) for the treatment of schizophrenia in adolescents aged $\geq 15$ years and for the treatment of moderate to severe manic episodes associated with a bipolar I disorder for up to 12 weeks in adolescents aged $\geq 13$ years. The EMA does not recommend the use of aripiprazole in patients aged $<13$ years because of the increased risk of adverse events associated with the drug in younger patients [1].

Aripiprazole is an atypical antipsychotic. The efficacy of antipsychotics in general is thought to be mediated mainly by $\mathrm{D}_{2}$ dopamine receptor antagonism in the mesolimbic brain region, targeting pathways that at least partly mediate psychosis, mania, tics, and aggression. In addition, atypical antipsychotics exert pharmacodynamic activity at other receptors. The efficacy, safety, and tolerability of each individual antipsychotic can ultimately be explained by its unique binding properties and their interactions with dopaminergic, noradrenergic, serotonergic, histaminergic, and cholinergic receptors. For example, dopaminergic pathways mediating motor movements, prolactin secretion, cognition, and motivation can be influenced, resulting in adverse effects such as extrapyramidal symptoms (EPS), increased prolactin levels, and neurolepsis (characterized by apathy, anhedonia, amotivation, and social withdrawal). Another example is the undesired blockade of histaminergic $\mathrm{H}_{1}$ receptors, leading to weight gain $[5,6]$.
The FDA recently sent a warning of new potential side effects: compulsive or uncontrollable urges to gamble, binge eat, shop, and have sex have been reported with the use of aripiprazole. These will be added to the drug labels and the patient medication guides as potential side effects for all aripiprazole products [79].

The incidence of side effects can vary substantially, depending on, for example, differences in antipsychotic dose. Age and development can also influence susceptibility to adverse effects. Children and adolescents treated with aripiprazole are more vulnerable than older patients to weight gain and other metabolic side effects [8]. In general, younger patients (aged $<20$ years) are also more likely to experience EPS [7].

EPS can manifest early or in the longer term after commencing antipsychotic treatment. Tardive dyskinesia is one of the late variants of EPS. Early EPS can be further divided into three categories: (acute) dystonia, (acute) akathisia, and parkinsonism (tremor, bradykinesia/hypokinesia, rigidity) [7]. Dystonia usually manifests early in therapy [3], fluctuates with stress and relaxation [9], and is characterized by abnormal and sustained contractions of muscle groups in the head, neck, back, eyes, and limbs [10]. This may result in torticollis, cramps, and pain in the head, neck, and back; oculogyric crises; and potentially lethal respiratory stridor if pharyngeal or laryngeal musculature is affected. Parkinsonism also occurs early after administration of antipsychotic drugs. Akathisia may begin early in treatment, but the onset may also be delayed [11]. Akathisia is defined by the subjective feeling of restlessness, often accompanied by the urge to move and inability to sit still $[9,10]$. The symptoms more often affect the lower extremities and vary with stress and arousal [9]. Atypical antipsychotics seem to be an attractive alternative to typical antipsychotics because of the promise of fewer EPS for equal efficacy [5, 12]. Within the group of atypical antipsychotics, aripiprazole is considered to lead to relatively minimal metabolic side effects and prolactin increases $[3,4,8,11,13]$. The perceived favorable risk profile has led to an increase in the use of aripiprazole in youth for both official and off-label indications (anxiety, eating, personality disorders, Gilles de la Tourette syndrome, etc.) $[14,15]$.

However, some authors have questioned the assumed favorable EPS profile of atypical antipsychotics as a group relative to the typical antipsychotics (prototype: haloperidol) $[9,13]$. Such reservations are relevant to children, adolescents, and adults. Given this, and the increased use of aripiprazole in pediatric patients, we wished to investigate the risk of children and adolescents developing (acute) EPS when treated with aripiprazole. Therefore, we conducted a meta-analysis to assess the evidence for acute EPS associated with the use of the drug in this patient group. 


\section{Methods}

\subsection{Search}

We searched the English, French, and Dutch literature via PubMed and Embase from 2003 until 10 April 2016. A first explorative search did not reveal many relevant hits, so we imposed minimum constraints on our eligibility criteria, e.g. we did not define comparator treatments in advance or limit our search to one manifestation of EPS.

Eligibility criteria are described according to the PICOS structure (population, intervention, comparators, outcomes, study design). Specifically, published studies in human subjects were eligible if the following criteria were met:

- Population: children and adolescents aged $<18$ years were considered.

- Interventions/comparisons: treatment with aripiprazole (regardless of the formulation) was considered; comparator treatments were not defined in advance.

- Outcomes: to account for all manifestations of (acute) EPS, we used the key term "extrapyramidal symptoms".

\subsection{Study Selection}

We used the following exclusion criteria to evaluate the abstracts of papers identified by the initial search for relevance to the study question: (1) study design: case report, case series, letter to the editor, editorial, or data solely presented by means of a poster presentation; (2) unrelated PICOS structure, e.g. another antipsychotic or a combination therapy was studied, the study focused on other side effects or on efficacy of treatment rather than on safety and tolerability, or the (mean) age of the study participants was $>18$ years. We also manually searched the reference lists of review papers to ensure all relevant studies were included.

This study was conducted in accordance with the Declaration of Helsinki and approved by the Ethical Guidance Committee of the Faculty of Medicine, KU Leuven, Belgium.

\subsection{Methodological Quality Assessment}

We used the Jadad scale [80] to assess the quality of randomized studies. Depending on the description of the randomization method, double blinding, and the description of dropouts and withdrawals, an overall quality score ranging from 0 (weakest score) to 5 (strongest score) was assigned to the individual studies. We only included studies scoring $\geq 3$ points in our analysis, as studies with this score are usually considered of adequate trial quality.

Although the use of scales to assess study quality is common and appealing because of their simplicity, some disadvantages need to be taken into account. The Cochrane Handbook for Systematic Reviews of Interventions alerts us to some of the risks inherent to the use of scales to assess quality. For example, "calculating a summary score inevitably involves assigning 'weights' to different items in the scale," which makes it "difficult to justify the weights assigned" and scales "are less likely to be transparent to users of the review" [81]. Consequently, the authors express their preference for a detailed description (i.e., "how each trial was rated on each criterion") of the quality assessment approach.

Several instruments have been developed to assess the methodological quality of non-randomized studies of interventions. Again, the Cochrane Handbook for Systematic Reviews of Interventions advises review authors to use these instruments with caution [81]. We were unable to find a tool appropriate for use with all the different designs in the non-randomized studies included in our meta-analysis. Therefore, we provide the reader with a description of quality items for each study (see the Electronic Supplementary Material [ESM]). Based on the work of Gearing et al. [82] and Vassar and Holzmann [83], we identified six domains underpinning the methodological quality assessment of retrospective chart reviews: research question, sample, exclusion criteria, operationalization of the concept (EPS), data abstraction, and confidentiality issues, and/or ethical considerations. The methodological quality assessment of the other studies was based on the Newcastle-Ottawa Scale (the version for cohort studies) [84] and the quality rating criteria mentioned by Forbes and Griffiths [85]. Finally, information regarding potential sources of support in the included studies is listed in the ESM.

\subsection{Data Extraction}

We extracted the following information: study characteristics (year of publication, study design, study duration), study population characteristics (main diagnosis according to the Diagnostic and Statistical Manual of Mental Disorders, fourth edition, text revision [DSM-IVTR], sex, age), number of children and/or adolescents investigated, measuring methods used to assess the incidence of EPS, dose of aripiprazole, and the incidence of EPS and its manifestations. We contacted the authors of identified studies via e-mail to obtain unpublished data. 


\subsection{Statistical Analysis}

We performed a meta-analysis based on the available studies described above to obtain an optimal estimation of the incidence of EPS in children and adolescents treated with aripiprazole. The effect size used for the incidence of EPS was the proportion, but all analyses were performed, converting proportions into logits. Logits are preferred over proportions because the mean proportion across studies underestimates the size of the confidence interval (CI) around the mean proportion (due to the compression of the standard error as $\mathrm{p}$ approaches 0 or 1) and overestimates the degree of heterogeneity across effect sizes [16]. Lipsey and Wilson [16] note this is especially the case when the observed proportions are $<0.2$ or $>0.80$, as was the case in some of the included studies. The logit method circumvents these problems and is the preferred method. However, for ease of interpretation, we converted all final results back into proportions.

We used a Q-statistic to examine the homogeneity of the effect size distribution [17]. When we observed heterogeneity in effect sizes, we assessed the possible influence of moderator variables (age and sex of study population, aripiprazole dose, study duration, and tools used to detect EPS) and evaluated the suitability of either a fixed, random, or mixed model.

We included study duration as a categorical variable: short duration ( $\leq 12$ weeks), medium duration $(>13$ and $<26$ weeks), and long duration ( $\geq 26$ weeks).

We used measurement data to develop a binary variable (making use of history taking and clinical examination with or without conducting additional questionnaires). The included studies used a range of different questionnaires: the Simpson Angus Scale (SAS) [18], the Abnormal Involuntary Movement Scale (AIMS) [19], the Extrapyramidal Symptom Rating Scale (ESRS) [20], the Barnes Akathisia Rating Scale (BARS) [21], the Udvalg for Kliniske Undersøgelser side effect rating scale (UKU) [22], the Treatment Emergent Symptoms Scale (TESS) [78], and/or the Safety Monitoring Uniform Research Form (SMURF) [23]. The AIMS is used to detect the presence of 'tardive dyskinesia', a rather late-appearing manifestation of EPS [10].

Furthermore, we conducted a subgroup analysis to compare the incidence of EPS and of several EPS manifestations (dystonia, akathisia, parkinsonism, tremor, and tardive dyskinesia) in the included placebo-controlled trials [24-31]. We chose to omit the study by Findling et al. [74] from this subgroup analysis because no clear distinction in observed adverse events between the placebo group and the aripiprazole group could be made. The authors themselves acknowledged that "potentially a portion of the adverse events observed in the placebo arm may stem from residual exposure to aripiprazole in phase 1" [74].

We calculated effect sizes as the natural logarithm of the odds ratios (ORs) but converted the mean and CIs back into ORs to report the final results.

If we could not calculate an OR in some studies because certain frequencies were equal to zero, we added 0.5 to these 'zero frequencies' to facilitate a calculation of the OR. This procedure may lead to an underestimation of the effect size, but it gives an acceptable estimate of the effect size if the number of 'zero frequencies' is low [32].

\section{Results}

An initial search via PubMed and Embase yielded 328 hits (53 hits in PubMed and 297 hits in Embase; 22 duplicates). Consistent with the above-mentioned inclusion and exclusion criteria, we excluded 151 records according to title and/or abstract and 104 records because of study design and/or unrelated PICOS structure. We further evaluated all 73 potentially relevant full-text articles in detail and excluded an additional 34 publications. Manual search of the reference lists of review papers identified an additional seven relevant articles. We included 46 publications in the analysis, but not all studies had data that could be used in the meta-analysis (see Fig. 1) [24-31, 33-37, 43, 45, 46, 48-77]. See the ESM for a list of the excluded studies (according to study design and/or unrelated PICOS structure). We did not restrict our search to studies assessing oral aripiprazole; however, no studies assessed the long-acting injectable formulation of the drug in participants aged $<18$ years.

All of the nine included randomized controlled trials [24-31, 74] had a Jadad score $\geq 3$ and were considered to be of adequate trial quality (see Table S2 in the ESM).

The overall methodological quality of the included nonrandomized studies (retrospective chart reviews $[34,36,48,50,52,63,67]$; other non-randomized studies $[33,35,37,43,45,46,49,51,53-62,64-66$, $68,73,75,76]$ ) was low to moderate (see Table $S 3$ in the ESM).

The meta-analysis includes 41 studies [24-31, 33-37, 43, 45, 46, 48-68, 73-76], with a total of 2114 pediatric patients (see Table S1 in the ESM). Of the 41 studies included, 37 [24-31, 33-37, 43, 45, 46, $48-59,62,65-68,73-76$ ] described the mean age of the participants. The weighted average age was 11.7 years, with a few outliers: Findling and colleagues [26, 33] focused on participants aged 4-9 years, Bildik et al. [34] focused on adolescents aged 15-19 years, and the mean age in the study by Woods et al. [35] was 17.1 years. 
Fig. 1 Flow chart of the study selection. PICOS population, intervention, comparators, outcomes, study

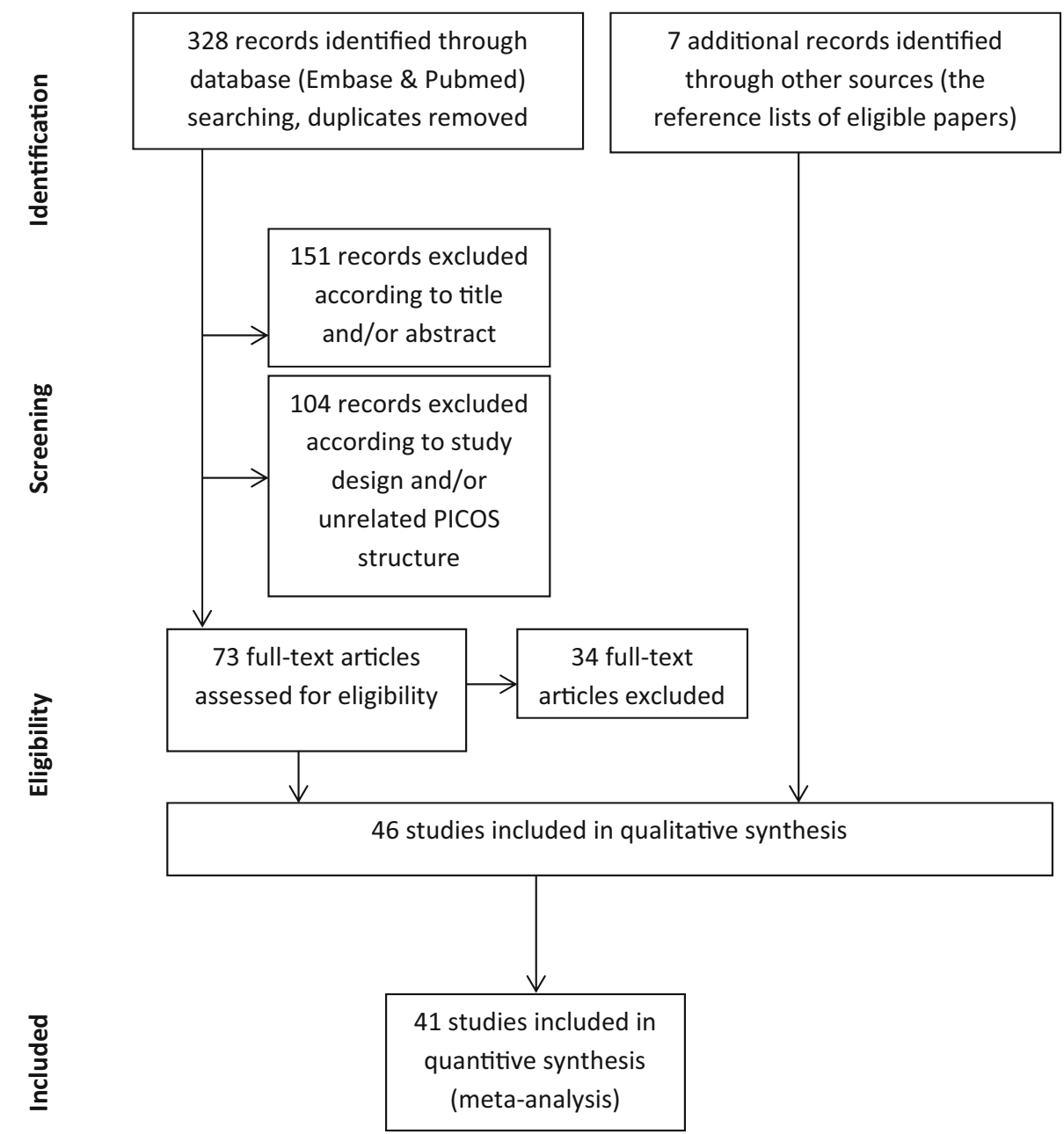

A total of $72 \%$ of participants were male. The population of most studies consisted mainly of boys, except those of Bildik et al. [34], Gibson et al. [36], and Tramontina et al. [30].

For the analysis of the mean EPS incidence, data were provided by 24 studies $(N)$, with a total of 1446 pediatric patients $(n) \quad[25, \quad 27-30,33,36,37,43,45$, 49-51, 53-56, 58, 60, 61, 63, 65, 68, 74]. Meta-analysis revealed a mean EPS incidence of $17.1 \%$ (95\% CI 0.128-0.223) (Table 1). We calculated the incidence of akathisia in 24 trials, with 1660 patients [24-31, 33-36, 46, 48, 52, 54, 55, 57, 58, 64, 66, 68, 73, 75]. Metaanalysis revealed a mean akathisia incidence of $8.8 \%(95$ $\%$ CI 0.059-0.130). The mean incidence of dystonia, parkinsonism, tremor, and tardive dyskinesia could only be analysed in a smaller group of patients because available data were limited. The mean incidence of tardive dyskinesia was $1.7 \%$ (95\% CI $0.010-0.028 ; N=15, n=1261)$ [24-27, 30, 33, 34, 46, 55, 56, 58, 65, 67, 68, 73], the mean incidence of tremor was $10.5 \%(95 \%$ CI $0.065-0.165 ; N=$ $17, n=1055)[24,28-30,34,48,50,55-59,62,65$,
$66,68,76]$, the mean incidence of dystonia was $4.8 \%(95$ $\%$ CI $0.026-0.087 ; N=11, n=785)[24,25,27,29$, $31,34,46,48,55,64,68]$, and the mean incidence of parkinsonism was $20.8 \%(95 \%$ CI $0.159-0.269 ; N=10$, $n=755)[24,25,27,45,46,52,55,56,68,73]$.

Table 1 shows the effect sizes and $95 \%$ CIs (in percentages) of the incidence of EPS, its three main categories (dystonia, akathisia, and parkinsonism), tremor, and tardive dyskinesia (in the total sample as well as in the subgroup of placebo-controlled trials).

The Q-statistic showed that variability in effect size between the studies was higher than would be expected on the basis of sampling error, for the analysis of both the incidence of EPS and that of dystonia, akathisia, parkinsonism, and tremor. For these extrapyramidal side effects, we assessed the possible influence of moderator variables (age and sex of study population, aripiprazole dose, study duration, and tools to detect EPS). In terms of incidence of various extrapyramidal side effects, overall, no significant effects of age, sex, mean dose, study duration, or measuring method could be demonstrated. 
Table 1 Effect sizes and $95 \%$ confidence intervals

\begin{tabular}{llrc}
\hline Extrapyramidal side effect & Model & $\begin{array}{l}\text { Studies } \\
(N)\end{array}$ & $\begin{array}{l}\text { Point estimate } \\
\%(95 \% \mathrm{CI})\end{array}$ \\
\hline EPS & Random & 24 & $17.1(12.8-22.3)$ \\
EPS (PCT) & Fixed & 5 & $26.3(22.8-30.2)$ \\
& Random & 5 & $25.5(19.0-31.0)$ \\
Dystonia & Random & 11 & $4.8(2.6-8.7)$ \\
Dystonia (PCT) & Fixed & 5 & $3.5(2.3-5.4)$ \\
& Random & 5 & $3.5(2.3-5.4)$ \\
Akathisia & Random & 24 & $8.8(5.9-13.0)$ \\
Akathisia (PCT) & Fixed & 8 & $9.4(7.5-11.9)$ \\
& Random & 8 & $7.6(4.8-11.9)$ \\
Parkinsonism & Random & 10 & $20.8(15.9-26.9)$ \\
Parkinsonism (PCT) & Fixed & 3 & $22(18.7-25.7)$ \\
& Random & 3 & $22(18.7-25.7)$ \\
Tremor & Random & 17 & $10.5(6.5-16.5)$ \\
Tremor (PCT) & Fixed & 4 & $10.5(7.8-14)$ \\
& Random & 4 & $12.4(6.1-23.8)$ \\
Tardive dyskinesia & Random & 15 & $1.7(0.10-2.8)$ \\
Tardive dyskinesia (PCT) & Fixed & 5 & $1.2(0.6-2.6)$ \\
& Random & 5 & $1.2(0.6-2.6)$ \\
\hline Cr & 5 (P)
\end{tabular}

$C I$ confidence interval, $E P S$ extrapyramidal symptoms, $P C T$ subgroup analysis of the placebo-controlled trials

Table 2 represents the comparison between the incidence of EPS, dystonia, akathisia, parkinsonism, tremor, and tardive dyskinesia in the placebo-controlled trials. The results are presented as ORs of aripiprazole versus placebo. Only the side effects 'EPS', 'parkinsonism', and 'tremor' were significantly more common in children and adolescents treated with aripiprazole than in those receiving placebo. The Q-statistic did not show heterogeneity for any of these side effects, but the small number of trials mean this can be unreliable.
The funnel plot (Fig. 2) illustrates that studies with a lower incidence of EPS are over-represented in our analysis, which may indicate publication bias. There was also one positive outlier (Lyon et al. [37]). Figure 3 presents the mean incidence of EPS in children and adolescents treated with aripiprazole (17\%; $95 \%$ CI $0.13-0.22)$ as a forest plot. The mean incidences of the three main categories of EPS are also displayed graphically (Figs. S1-3 in the ESM).

\section{Discussion}

The primary objective of this analysis was to assess the evidence for (acute) EPS associated with the use of aripiprazole in children and adolescents given the assumed favorable side-effect profile of atypical antipsychotics as a group relative to typical antipsychotics [5]. Within the group of atypical antipsychotics, aripiprazole is considered to lead to relatively minimal metabolic side effects and prolactin increases $[3,4,8,11,13]$. Does the same apply to the extrapyramidal side effects? Some authors suggest a lower risk of EPS for certain atypical antipsychotics. Studies showed a lower risk of emerging EPS in patients treated with quetiapine or clozapine and a higher risk with ziprasidone, olanzapine, aripiprazole, and risperidone $[4,11,38,39]$.

This study reveals that the incidence of EPS in children and adolescents treated with aripiprazole is not negligible. Our meta-analysis indicates a mean EPS incidence of $17.1 \%$. The summary of the European Public Assessment Report (EPAR) for Abilify ${ }^{\circledR}$ (aripiprazole) notes incidence figures in pediatric patients in line with our findings. These figures are based on individual studies [1].

Table 2 Comparison between the incidences of extrapyramidal symptoms in the placebo-controlled trails: odds ratios

\begin{tabular}{|c|c|c|c|c|c|c|c|}
\hline & Model & Studies $(n)$ & $\begin{array}{l}\text { Point estimate } \\
(95 \% \mathrm{CI})\end{array}$ & $Z$ & $p$ value & Q-statistic & $\mathrm{p}$ value $\mathrm{Q}$-statistic \\
\hline \multirow[t]{2}{*}{ EPS } & Fixed & 5 & $3.85(2.37-6.28)$ & 5.42 & 0.00 & 4.04 & 0.40 \\
\hline & Random & 5 & $3.85(2.36-6.30)$ & 5.37 & 0.00 & & \\
\hline \multirow[t]{2}{*}{ Dystonia } & Fixed & 5 & $1.35(0.52-3.48)$ & 0.61 & 0.54 & 3.80 & 0.43 \\
\hline & Random & 5 & $1.35(0.52-3.48)$ & 0.61 & 0.54 & & \\
\hline \multirow[t]{2}{*}{ Akathisia } & Fixed & 8 & $1.38(0.77-2.47)$ & 1.07 & 0.29 & 13.05 & 0.07 \\
\hline & Random & 8 & $1.29(0.54-3.12)$ & 0.57 & 0.57 & & \\
\hline \multirow[t]{2}{*}{ Parkinsonism } & Fixed & 3 & $4.91(2.76-8.75)$ & 5.40 & 0.00 & 0.58 & 0.75 \\
\hline & Random & 3 & $4.91(2.76-8.75)$ & 5.40 & 0.00 & & \\
\hline \multirow[t]{2}{*}{ Tremor } & Fixed & 4 & $3.46(1.42-8.43)$ & 2.73 & 0.01 & 1.97 & 0.58 \\
\hline & Random & 4 & $3.46(1.42-8.43)$ & 2.73 & 0.01 & & \\
\hline \multirow[t]{2}{*}{ Tardive dyskinesia } & Fixed & 5 & $1.92(0.43-8.59)$ & 0.85 & 0.39 & 0.37 & 0.99 \\
\hline & Random & 5 & $1.92(0.43-8.59)$ & 0.85 & 0.39 & & \\
\hline
\end{tabular}

CI confidence interval, EPS extrapyramidal symptoms 
Fig. 2 Asymmetric funnel plot of the included studies
Fig. 3 Forest plot of the mean incidence of extrapyramidal symptoms in children and adolescents treated with aripiprazole without the positive outlier. $C I$ confidence interval
Funnel Plot of Standard Error by Logit event rate
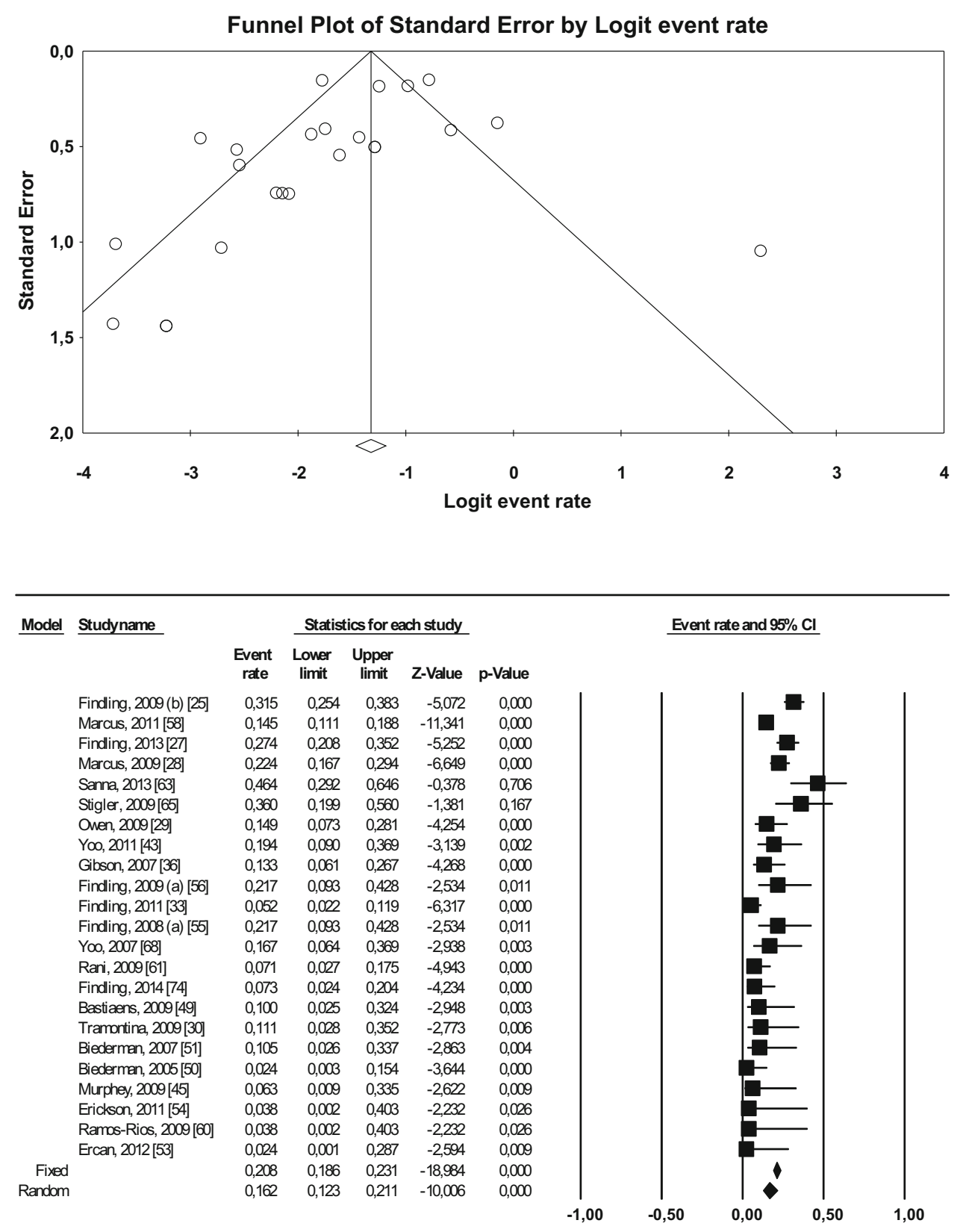

Meta Analysis

Ching and Pringsheim [40] undertook a Cochrane review and also suggested a higher percentage of EPS in children and adolescents with autism spectrum disorders treated with aripiprazole than in those receiving placebo (risk ratio $1.8 ; 95 \% \mathrm{CI} 0.98-3.66 ; P=0.06$ ). It is possible that the result did not reach statistical significance because of a lack of power with only two included studies.

Children and adolescents seem to be as sensitive as adults to developing EPS when treated with aripiprazole. The Abilify ${ }^{\circledR}$ summary of product characteristics reports an
EPS incidence of 18.2-26.6 \% in adult patients with a manic episode of a bipolar I disorder and $14.8-25.8 \%$ in adult patients with schizophrenia. These figures are also based on individual studies [1].

In contrast, some authors note a higher sensitivity in the pediatric population for the development of EPS under treatment with (atypical) antipsychotics [12]. Differences in pharmacokinetics, in dopaminergic receptor density (which is inversely proportional to age), and pharmacodynamics have been suggested as possible explanations $[38,41]$. The 
EPAR summary [1] describes a higher risk of developing acute dystonia in younger age groups, particularly with aripiprazole. Our analysis did not reveal a significant effect of age on the various extrapyramidal side effects.

The meta-analysis by Cohen et al. [4] revealed a significant increase in EPS in children and adolescents treated with atypical antipsychotics versus placebo, except for quetiapine, noting the following ORs: ziprasidone (20.56; $95 \%$ credible interval [CrI] 3.53-68.94), olanzapine (OR 6.36; $95 \%$ CrI 2.43-13.84), aripiprazole (OR 3.79; $95 \%$ CrI 2.17-6.17), risperidone (OR 3.71; $95 \%$ CrI 2.18-6.02), and quetiapine (OR 2.54; $95 \%$ CrI 0.88-6.07). The analysis did not include clozapine.

These findings are in accordance with our data. We conducted a subgroup analysis of the included placebocontrolled trials to compare the incidence of EPS. Aripiprazole significantly increased the risk of EPS (OR 3.85; $95 \%$ CI 2.37-6.28). Although aripiprazole is supposed to lead to relatively minimal metabolic side effects and prolactin increases $[3,4,8,11,13]$, the risk of extrapyramidal side effects seems to be in line with that of other atypical antipsychotics (e.g., risperidone).

Kumar et al. [42] reported on the efficacy and tolerability of atypical antipsychotics in adolescents with psychosis. Only one included study compared the incidence of (acute) EPS between patients treated with an atypical antipsychotic (risperidone) and those treated with a typical antipsychotic (perphenazine) (risk ratio 0.37; $95 \%$ CI $0.20-0.68$ ). Furthermore, only one study [43] in our analysis compared treatment with an atypical antipsychotic (aripiprazole) with treatment with a typical antipsychotic (haloperidol) (OR 0.343; $95 \%$ CI 0.092-1.276).

In terms of the incidence of the various extrapyramidal side effects, we found no significant effects of the other moderator variables (sex, mean dose, study duration, and measuring method), despite (sporadic) suggestive findings in literature. For example, the EPAR summary [1] suggests that men have a higher risk of developing acute dystonia. Argyriou et al. [44] and EMA [1] mention a positive doseresponse relationship in children and adolescents: a higher dose of aripiprazole is supposed to increase the incidence of EPS. For this reason, the FDA [2] recommends a daily dose of $10 \mathrm{mg}$ (with a maximum of $30 \mathrm{mg} /$ day). In our analysis, the mean daily doses ranged between 3.3 [45] and $24.52 \mathrm{mg}$ [46]. We found no daily intakes of $30 \mathrm{mg}$, which possibly led to the lack of a potential dose-response relationship in our analysis. Moreover, most of the included trials used flexible dosing. Only a fixed- and multiple-dose study can address the issue of the dose relationship with outcome. Further research is recommended.

Since the Q-statistic did not reveal heterogeneity, we did not assess the possible influence of any moderator variable on the incidence of tardive dyskinesia. A possible explanation could be the small number of trials, which makes the Q-statistic unreliable.

Overall, the severity of EPS was described as mild to moderate, transient, and treatable (if necessary). EPS can be screened for in several ways, which is reflected in the non-uniform registration of EPS in the different study populations. One method of screening is assisted self-reporting by parents/children, or-preferably-a combination of both. When no input from the child is possible, the child's guardian is surveyed; this only happened in exceptional situations. A second option to screen for EPS is by (hetero-)anamnesis. The researcher could explicitly ask for the occurrence of EPS in its various manifestations. A supplementary clinical neurological examination could be conducted. Particular attention should be given to the following: mental status, cranial nerves, motor examination, coordination and gait, and a general observation of the patient (e.g., "are abnormal movements noted?") [47]. Some structured questionnaires, such as the BARS [21] and the ESRS [20], consist of (hetero)-anamnesis and a clinical neurological examination combined. It is important to highlight that the SAS [18], the ESRS [20], the BARS [21], and the AIMS [19] have been neither validated nor developed specifically for pediatric use [47]. This is why Correll et al. [38] suggest use of the SMURF [23], a standardized pediatric side-effect scale. Based on these questionnaires, researchers can screen for EPS in a structured way and may qualify and quantify the retrieved EPS whereby severity can be assessed.

\subsection{Limitations}

Most of the limitations are linked to the nature of the included studies. First, the definition of extrapyramidal side effects varies across studies. This could be because of the various screening methods used to detect EPS. In addition to (hetero)-anamnesis and clinical neurological examination, one or more structured questionnaires are often used. The SAS [18], the BARS [21], and the AIMS [19] are the most common, but other questionnaires and multiple combinations thereof are also used. More specifically, the symptom 'tremor' can be defined in different ways. Although tremor can be a symptom of medication-induced parkinsonism, a (fine) tremor can also arise when a subject tries to maintain a certain position ('medication-induced postural tremor', no manifestation of EPS) [10]. With a few exceptions, this distinction was not described.

Second, many of the included studies allowed the use of concomitant medication (e.g., anticholinergics). Because of the inconsistent reporting, we were unable to assess the influence of this possible moderator variable. The same applies to the reporting of participant drug history (e.g., antipsychotic naïve or not), which may have affected our results. 
Another limitation is that a well-defined length of exposure to aripiprazole was lacking, with many studies mentioning only study duration. The influence of this possible moderator variable could not be assessed.

Most of the included studies were short in duration. Therefore, we were unable to explore any possible longterm side effects, despite our concern about the impact this drug can exert on the developing brain as it targets the transmitter pathways in the central nervous system [38].

Next, the majority of included studies had small study populations, limiting their power. In fact, the overall lower quality of the included studies is an important limitation. Study design was very heterogeneous (retrospective vs. prospective, randomized vs. not, with or without a control group, placebo controlled vs. active comparator controlled, etc.), as was their internal validity. Head-to-head comparisons of the different antipsychotics were rare.

Finally, the methodology of our literature review and meta-analysis include some further inherent limitations. First, only on researcher performed both the selection of studies and the assessment of methodological quality. Second, a selection bias may have been introduced with the exclusion of studies. The possibility of publication bias must also be taken into account, because studies with a lower incidence of EPS were over-represented in our analysis. It is possible that the found mean incidence of EPS in children and adolescents treated with aripiprazole is underestimated.

\section{Conclusion}

In recent years, the use of aripiprazole in youth, for both official and off-label indications (anxiety, eating, personality disorders, Gilles de la Tourette syndrome, etc.) [14], has increased because of the perceived favorable risk profile. However, the assumed favorable side-effect profile of atypical antipsychotics as a group relative to the typical antipsychotics has recently been questioned [9, 13]. Our meta-analysis supports these recent concerns, as it reveals a mean EPS incidence in children and adolescents treated with aripiprazole of $17.1 \%$ (95\% CI 0.128-0.223). This finding highlights the importance of further research in this field, especially considering the significance of how negatively EPS can impact patient quality of life (e.g., through stigmatization, stress and anxiety, and potentially lifethreatening events, for example the emergence of laryngospasm) [3]. Randomized, (double) blinded, placebocontrolled/multi-arm, head-to-head comparator studies with long-term follow-up and large study populations with subjects of both sexes are urgently needed. Furthermore, a more precise definition and operationalization of the concept of EPS and of its measurement is necessary. The research setting should mimic a clinical setting as closely as possible. This may lead to the identification of potential risk factors in specific subsets of pediatric patients with the aim of predicting and even preventing the onset of extrapyramidal side effects from treatment with atypical antipsychotics (including aripiprazole).

Each antipsychotic has a unique profile of (side) effects. Besides the risk of the onset of EPS, the risk of emerging metabolic side effects and hyperprolactinemia also plays an important role in the choice of therapy. Atypical antipsychotics should be prescribed with caution in children and adolescents. Hopefully, in the near future, our findings and further research will provide more individualized guidelines to assist clinicians, together with the patient and guardians, to make well-balanced treatment choices.

In addition, given the non-negligible incidence of EPS found in our analysis, clinicians are urged to undertake more targeted medication monitoring in clinical practice. For example, we recommend using the SMURF [23], a standardized pediatric side-effect scale.

Acknowledgments The authors would like to thank M. Stroobants (Library of Medicine, UPC KU Leuven-Z.org KU Leuven) for his assistance in tracing publications and Dr. K. Abrahams, medical student in residency (KU Leuven), for her contributions to the background research. The authors also wish to thank Dr. I. Vandenbussche, child and adolescent psychiatrist, for her support.

\section{Compliance with Ethical Standards}

Funding UPC KU Leuven funded the open access fee.

Conflict of interest Professor Marc De Hert has been a consultant for, received grant and/or research support and honoraria from, and participated on the speakers' bureaus and/or advisory boards of the following companies: Janssen-Cilag, Lundbeck, Otsuka, and Takeda. Professor Marina Danckaerts has received research support from Janssen-Cilag and Shire, has been a member of the advisory board of Shire and Neurotech Solutions, and has participated on the speakers' bureaus of Shire, Novartis, and Medice. Dr. Chiara Bernagie, MD/ Ph.D.-student, and Martien Wampers, Ph.D., have no financial ties or conflicts of interest to disclose.

Open Access This article is distributed under the terms of the Creative Commons Attribution-NonCommercial 4.0 International License (http://creativecommons.org/licenses/by-nc/4.0/), which permits any noncommercial use, distribution, and reproduction in any medium, provided you give appropriate credit to the original author(s) and the source, provide a link to the Creative Commons license, and indicate if changes were made.

\section{References}

1. European Medicines Agency. Summary of product characteristics. Abilify: European Public Assessment Report. http://www. ema.europa.eu/docs/en_GB/document_library/EPAR_-_Product_ 
Information/human/000471/WC500020170.pdf. Accessed 8 Oct 2013.

2. US Food and Drugs Administration. Prescribing information: Abilify. http://www.accessdata.fda.gov/drugsatfda_docs/label/ 2013/021436s037,021713s029,021729s021,021866s022lbl.pdf. Accessed 30 July 2013

3. Ben Amor L. Antipsychotics in pediatric and adolescent patients: a review of comparative safety data. J Affect Disord. 2012;138:S22-30.

4. Cohen D, Bonnot O, Bodeau N, Consoli A, Laurent C. Adverse effects of second-generation antipsychotics in children and adolescents: a Bayesian meta-analysis. J Clin Psychopharmacol. 2012;32:309-16.

5. Stahl SM. Stahl's essential psychopharmacology: neuroscientific basis and practical applications. 4th ed. Cambridge: Cambridge University Press; 2013.

6. Correll CU. From receptor pharmacology to improved outcomes: individualizing the selection, dosing, and switching of antipsychotics. Eur Psychiatry. 2010;25:S12-21.

7. Belgisch Centrum voor Farmacotherapeutische Informatie (BCFI), Gecommentarieerd Geneesmiddelenrepertorium. http:// www.bcfi.be/nl/articles/982?folia=925. Accesed April 2014.

8. De Hert M, Dobbelaere M, Sheridan EM, Cohen D, Correll CU. Metabolic and endocrine adverse effects of second-generation antipsychotics in children and adolescents: a systematic review of randomized, placebo controlled trials and guidelines for clinical practice. Eur Psychiatry. 2011;26(3):144-58.

9. Caroff SN, Hurford I, Lybrand J, Campbell EC. Movement disorders induced by antipsychotic drugs: implications of the CATIE Schizophrenia Trial. Neurol Clin. 2011;29(1):127-48.

10. American Psychiatric Association. Diagnostic and statistical manual of mental disorders. 5th ed. Arlington: American Psychiatric Association; 2013.

11. Correll CU. Antipsychotic use in children and adolescents: minimizing adverse effect to maximize outcomes. J Am Child Adolesc Psychiatry. 2008;47(1):9-20.

12. Kumra S, Oberstar JV, Sikich L, Findling RL, McClellan JM, Vinogradov S, et al. Efficacy and tolerability of second-generation antipsychotics in children and adolescents with schizophrenia. Schizophr Bull. 2008;34(1):60-71.

13. Leucht S, Cipriani A, Spineli L, Mavridis D, Örey D, Richter F, et al. Comparative efficacy and tolerability of 15 antipsychotic drugs in schizophrenia: a multiple-treatments meta-analysis. Lancet. 2013;382:951-62.

14. Guzman F. Aripiprazole indications: FDA-approved and off-label uses. Psychopharmacology Institute. http://psychopharmacology institute.com/antipsychotics/aripiprazole/aripiprazole-indicationsfda-approved-off-label-uses/. Accessed 9 Nov 2013.

15. Olfson M, King M, Schoenbaum M. Treatment of young people with antipsychotic medications in the United States. JAMA Psychiatry. 2015;72(9):867-74.

16. Lipsey M, Wilson D. The efficacy of psychological educational and behavioral treatment: confirmation from meta-analysis. Am Psychol. 1993;48:1181-209.

17. Hedges L, Olkin I. Statistical methods for meta-analysis. Orlando: Academic Press; 1985.

18. Simpson GM, Angus JW. A rating scale for extrapyramidal side effects. Acta Psychiatr Scand Suppl. 1970;45(212):11-9.

19. Guy W. ECDEU assessment manual for psychopharmacology. Rockville: National Institute of Mental Health; 1976. p. 338.

20. Chouinard G, Ross-Chouinard A, Annable L, Jones BD. Extrapyramidal symptom rating scale. Can J Neurol Sci. 1980;7:233.

21. Barnes TR. A rating scale for drug-induced akathisia. Br J Psychiatry. 1989;154(5):672-6.
22. Lingjaerde O, Ahlfors UG, Bech P, Dencker SJ, Elgen K. The UKU side effect rating scale. A new comprehensive rating scale for psychotropic drugs and a cross-sectional study of side effects in neuroleptic-treated patients. Acta Psychiatr Scand Suppl. 1987;334:1-100.

23. Greenhill LL, Vitiello B, Fisher P, Levine J, Davies M, Abikoff $\mathrm{H}$, et al. Comparison of increasingly detailed elicitation methods for the assessment of adverse events in pediatric psychopharmacology. J Am Acad Child Adolesc Psychiatry. 2004;43(12):1488-96.

24. Findling RL, Robb A, Nyilas M, Forbes RA, Jin N, Ivanova S, et al. A multiple-center, randomized, double-blind, placebocontrolled study of oral aripiprazole for treatment of adolescents with schizophrenia. Am J Psychiatry. 2008;165(11):1432-41.

25. Findling RL, Nyilas M, Forbes R, McQuade RD, Jin N, Iwamoto T, et al. Acute treatment of pediatric bipolar I disorder, manic or mixed episode, with aripiprazole: a randomized, double-blind, placebocontrolled study. J Clin Psychiatry. 2009;70(10):1441-51.

26. Findling RL, Youngstrom EA, McNamara NK, Stansbrey RJ, Wynbrandt JL, Adegbite C, et al. Double-blind, randomized, placebo-controlled long-term maintenance study of aripiprazole in children and adolescents with bipolar disorder. J Clin Psychiatry. 2012;73(1):57-63.

27. Findling RL, Correll CU, Nyilas M, Forbes RA, McQuade RD, Jin N, et al. Aripiprazole for the treatment of pediatric bipolar I disorder: a 30-week, randomized, placebo-controlled study. Bipolar Disord. 2013;15:138-49.

28. Marcus RN, Owen R, Kamen L, Manos G, McQuade RD, Carson $\mathrm{WH}$, et al. A placebo-controlled, fixed-dose study of aripiprazole in children and adolescents with irritability associated with autistic disorder. J Am Acad Child Adolesc Psychiatry. 2009;48(11):1110-9.

29. Owen R, Sikich L, Marcus RN, Corey-Lisle P, Manos G, McQuade RD, et al. Aripiprazole in the treatment of irritability in children and adolescents with autistic disorder. Pediatrics. 2009; 124(6): 1533-40.

30. Tramontina S, Zeni CP, Ketzer C, Pheula GF, Narvaez J, Rohde LA. Aripiprazole in children and adolescents with bipolar disorder comorbid with attention-deficit/hyperactivity disorder: a pilot randomized clinical trial. J Clin Psychiatry. 2009;70(5):756-64.

31. Yoo HK, Joung YS, Lee JS, Song DH, Lee YS, Kim JW, et al. A multicenter, randomized, double-blind, placebo-controlled study of aripiprazole in children and adolescents with Tourette's disorder. J Clin Psychiatry. 2013;74(8):e772-80.

32. Fleiss J. Measures of effect size for categorical data. In: Cooper $\mathrm{H}$, Hedges L, editors. The handbook of research synthesis. New York: Russell Sage Foundation; 1994. p. 245-60.

33. Findling RL, McNamara NK, Youngstrom EA, Stansbrey RJ, Frazier TW, Lingler J, et al. An open-label study of aripiprazole in children with a bipolar disorder. J Child Adolesc Psychopharmacol. 2011;21(4):345-51.

34. Bildik T, Ozbaran NB, Kose S, Cetin SK. Effectiveness and tolerability of aripiprazole in a real-world outpatient population of youth. Bull Clin Psychopharmacol. 2012;22(3):225-34.

35. Woods SW, Tully EM, Walsh BC, Hawkins KA, Callahan JL, Cohen SJ, et al. Aripiprazole in the treatment of the psychosis prodrome. An open-label pilot study. $\mathrm{Br} \mathrm{J}$ Psychiatry. 2007;191(Suppl. 51):S96-101.

36. Gibson AP, Crismon ML, Mican LM, Fischer C. Effectiveness and tolerability of aripiprazole in child and adolescent inpatients: a retrospective evaluation. Int Clin Psychopharmacol. 2007;22:101-5.

37. Lyon GJ, Samar S, Jummani R, Nirsch S, Spirgel A, Goldman R, et al. Aripiprazole in children and adolescents with Tourette's 
disorder: an open-label safety and tolerability study. J Child Adolesc Psychopharmacol. 2009;19(6):623-33.

38. Correll CU, Penzer JB, Parikh UH, Mughal T, Javed T, Carbon $\mathrm{M}$, et al. Recognizing and monitoring adverse events of secondgeneration antipsychotics in children and adolescents. Child Adolesc Psychiatr Clin N Am. 2006;15:177-206.

39. Pringsheim T, Panagiotopoulos C, Davidson J, Ho J, The Canadian Alliance for Monitoring Effectiveness and Safety of Antipsychotics in Children (CAMESA) guideline group. Evidence-based recommendations for monitoring safety of secondgeneration antipsychotics in children and youth. Paediatric Child Health. 2011;16(9):581-9.

40. Ching H, Pringsheim T. Aripiprazole for autism spectrum disorders (ASD). Cochrane Database Syst Rev. 2012;5:CD009043.

41. Memarzia J, Tracey D, Giaroli G. The use of antipsychotics in preschoolers: a veto or a sensible last option? J Psychopharmacol. 2014;28(4):303-19.

42. Kumar A, Datta SS, Wright SD, Furtado VA, Russell PS. Atypical antipsychotics for psychosis in adolescents. Cochrane Database Syst Rev. 2013;10:CD009582.

43. Yoo HK, Lee JS, Paik KW, Choi SH, Yoon SJ, Kim JE, et al. Open-label study comparing efficacy and tolerability of aripiprazole and haloperidol in the treatment of pediatric tic disorders. Eur Child Adolesc Psychiatry. 2011;20:127-35.

44. Argyriou E, Petroggona M, Charitaki S, Belivanaki M, Giannakopoulos G, Kolaitis G. Aripiprazole in children and adolescents with schizophrenia. Curr Psychopharmacol. 2012;1:117-21.

45. Murphey TK, Mutch J, Reid JM, Edge PJ, Storch EA, Bengtson $\mathrm{M}$, et al. Open label aripiprazole in the treatment of youth with tic disorders. J Child Adolesc Psychopharmacol. 2009;19(4):441-7.

46. Findling RL, Kauffman RE, Sallee FR, Carson WH, Nyilas M, Mallikaarjun S, et al. Tolerability and pharmacokinetics of aripiprazole in children and adolescents with psychiatric disorders: an open-label, dose escalation study. J Clin Psychopharmacol. 2008;28(4):441-6.

47. Pringsheim T, Doja A, Belanger S, Patten S, The Canadian Alliance for Monitoring Effectiveness and Safety of Antipsychotics in Children (CAMESA) guideline group. Treatment recommendations for extrapyramidal side effects associated with second-generation antipsychotic use in children and youth. Paediatr Child Health. 2011;16(9):590-8.

48. Barzman DH, DelBello MP, Kowatch RA, Gernert B, Fleck DE, Pathak S, Rappaport K, et al. The effectiveness and tolerability of aripiprazole for pediatric bipolar disorders: a retrospective chart review. J Child Adolesc Psychopharmacol. 2004;14(4):593-600.

49. Bastiaens L. A non-randomized, open study with aripiprazole and ziprasidone for the treatment of aggressive behavior in youth in a community clinic. Community Ment Health J. 2009;45:73-7.

50. Biederman J, McDonnell MA, Wozniak J, Spencer T, Aleardi M, Falzone R, et al. Aripiprazole in the treatment of pediatric bipolar disorder: a systematic chart review. CNS Spectr. 2005;10(2):141-8.

51. Biederman J, Mick E, Spencer T, Doyle R, Joshi G, Hammerness $\mathrm{P}$, et al. An open-label trial of aripiprazole monotherapy in children and adolescents with bipolar disorder. CNS Spectr. 2007;12(9):683-9.

52. Budman C, Coffey BJ, Shechter R, Schrock M, Wieland N, Spirgel A, et al. Aripiprazole in children and adolescents with tourette disorder with and without explosive outbursts. J Child Adolesc Psychopharmacol. 2008;18(5):509-15.

53. Ercan ES, Uysal T, Ercan E, Ardic UA. Aripiprazole in children and adolescents with conduct disorder: a single-center, open-label study. Pharmacopsychiatry. 2012;45(1):13-9.

54. Erickson CA, Stigler KA, Wink LK, Mullett JE, Kohn A, Posey DJ, et al. A prospective open-label study of aripiprazole in fragile X syndrome. Psychopharmacology. 2011;216:85-90.
55. Findling RL, Short EJ, Leskovec T, Townsend LD, Demeter CA, McNamara NK, et al. Aripiprazole in children with attentiondeficit/hyperactivity disorder. J Child Adolesc Psychopharmacol. 2008;18(4):347-54.

56. Findling RL, Kauffman R, Sallee FR, Salazar DE, Sahasrabudhe $\mathrm{V}$, Kollia G, et al. An open-label study of aripiprazole: pharmacokinetics, tolerability, and effectiveness in children and adolescents with conduct disorder. J Child Adolesc Psychopharmacol. 2009;19(4):431-9.

57. Kuperman S, Calarge C, Kolar A, Holman T, Barnett M, Perry P. An open-label trial of aripiprazole in the treatment of aggression in male adolescents diagnosed with conduct disorder. Ann Clin Psychiatry. 2011;23(4):270-6.

58. Marcus RN, Owen R, Manos G, Mankoski R, Kamen L, McQuade $\mathrm{RD}$, et al. Safety and tolerability of aripiprazole for irritability in pediatric patients with autistic disorder: a 52-week, open-label, multicenter study. J Clin Psychiatry. 2011;72(9):1270-6.

59. Masi G, Cosenza A, Millepiedi S, Muratori F, Pari C, Salvadori F. Aripiprazole monotherapy in children and young adolescents with pervasive developmental disorders: a retrospective study. CNS Drugs. 2009;23(6):511-21.

60. Ramos-Rios R, Gago-Ageitos AM, Vidal-Millares M, MazairaCastro JA, Dominguez-Santos MD. Clinical effects and tolerability of aripiprazole in children and adolescents with psychiatric disorders. Eur Neuropsychopharmacol. 2009;19:S691.

61. Rani FA, Byrne PJ, Murray ML, Carter P, Wong ICK. Paediatric Atypical Antipsychotic Monitoring Safety (PAMS) study: Pilot study in children and adolescents in secondary- and tertiary-care settings. Drug Saf. 2009;32(4):325-33.

62. Rugino TA, Janvier YM. Aripiprazole in children and adolescents: clinical experience. J Child Neurol. 2005;20:603-10.

63. Sanna E, Atzeni MG, Melis GL, Carucci S, Zuddas A. Tolerability, safety and efficacy of long term (at least 6 months) quetiapine and aripiprazole in children and adolescents. Eur Neuropsychopharmacol. 2013;23:S605-6.

64. Singh PP, Meshram GG. Observed frequency of adverse events associated with aripiprazole use in child and adolescent age group. Drug Saf. 2009;32(10):890.

65. Stigler KA, Diener JT, Kohn AE, Li L, Erickson CA, Posey DJ, et al. Aripiprazole in pervasive developmental disorder not otherwise specified and Asperger's disorder: a 14-week, prospective, open-label study. J Child Adolesc Psychopharmacol. 2009; 19(3):265-74.

66. Tramontina S, Zeni CP, Pheula GF, Ketzer C, Rohde LA. Aripiprazole in juvenile bipolar disorder comorbid with attentiondeficit/hyperactivity disorder: an open clinical trial. CNS Spectr. 2007;12(10):758-62.

67. Valicenti-McDermott MR, Demb H. Clinical effects and adverse reactions of off-label use of aripiprazole in children and adolescents with developmental disabilities. J Child Adolesc Psychopharmacol. 2006;16(5):549-60.

68. Yoo HK, Choi SH, Park S, Wang HR, Hong JP, Kim CY. An open-label study of the efficacy and tolerability of aripiprazole for children and adolescents with tic disorders. J Clin Psychiatry. 2007;68(7):1088-93.

69. Chevreuil C, Polard E, Lemonnier E, Guillemot P, Bentué-Ferrer D. Prescription de l'aripiprazole chez l'enfant et l'adolescent. Therapie. 2011;66(2):123-30.

70. Doey T. Aripiprazole in pediatric psychosis and bipolar disorder: a clinical review. J Affect Disord. 2012;138:S15-21.

71. Greenaway M, Elbe D. Focus on aripiprazole: a review of its use in child and adolescent psychiatry. J Can Acad Child Adolesc Psychiatry. 2009;18(3):250-60.

72. McKinney C, Renk K. Atypical antipsychotic medications in the management of disruptive behaviors in children: safety guidelines and recommendations. Clin Psychol Rev. 2011;31:465-71. 
73. Carbon M, Kapoor S, Sheridan E, Al-Jadiri A, Azzo S, et al. Neuromotor adverse effects in 342 youth during 12 weeks of naturalistic treatment with 5 second-generation antipsychotics. J Am Acad Child Adolesc Psychiatry. 2015;54(9):718-27.

74. Findling RL, Mankoski R, Timko K, Lears K, McCartney T, McQuade RD, et al. A randomized controlled trial investigating the safety and efficacy of aripiprazole in the long-term maintenance treatment of pediatric patients with irritability associated with autistic disorder. J Clin Psychiatry. 2014;75(1):22-30.

75. Basgul SS. Aripiprazole use in children and adolescents: a public hospital child psychiatry outpatient department's experience. Klinik Psikofarmakol Bulteni. 2014;24(1):31-8.

76. Masi G, Gagliano A, Siracusano R, Berloffa S, Calarese T, Ilardo G, et al. Aripiprazole in children with Tourette's disorder and comorbid attention-deficit/hyperactivity disorder: a 12-week, openlabel, preliminary study. J Child Adolesc Psychpharmacol. 2012;22(2):120-5.

77. Budman CL. The role of atypical antipsychotics for treatment of Tourette's syndrome: an overview. Drugs. 2014;74(11):117793.

78. Guy W. ECDEU Assessment Manual for Psychopharmacology (Revised). Rockville: National Institutes of Health; 1976.

79. US Food and Drug Administration. FDA Drug Safety Communication: FDA warns about new impulse-control problems associated with mental health drug aripiprazole (Abilify, Abilify Maintena, Aristada). http://www.fda.gov/Drugs/Drug
Safety/ucm498662.htm?source=govdelivery\&utm_medium=email \&utm_source=govdelivery\#collapseOne. Accessed 5 March 2016.

80. Jadad AR, Moore RA, Carroll D, Jenkinson C, Reynolds DJ, Gavaghan DJ, McQuay HJ. Assessing the quality of reports of randomized clinical trials: is blinding necessary? Control Clin Trials. 1996;17:1-12.

81. Higgins JPT, Green S, editors. Cochrane handbook for systematic reviews of interventions version 5.1.0 [updated March 2011]. The Cochrane Collaboration. 2011. http://www.cochrane-handbook. org. Accessed May 2016.

82. Gearing RE, Mian IA, Barber J, Ickowicz A. A methodology for conducting retrospective chart review research in child and adolescent psychiatry. J Can Acad Child Adolesc Psychiatry. 2006;15(3):126-34.

83. Vassar M, Holzmann M. The retrospective chart review: important methodological considerations. J Educ Eval Health Prof. 2013;10:12.

84. Wells GA, Shea B, O'Connell D, Peterson J, Welch V, Losos M, et al. The Newcastle-Ottawa Scale (NOS) for assessing the quality of nonrandomised studies in meta-analyses. Ottawa: Ottawa Hospital Research Institute, 2011. http://www.ohri.ca/programs/ clinical_epidemiology/oxford.asp. Accessed 9 May 2016.

85. Forbes A, Griffiths P. Methodological strategies for the identification and synthesis of 'evidence' to support decision-making in relation to complex healthcare systems and practices. Nurs Inq. 2002;9:141-55. 